\title{
Extracorporeal life support after staged palliation of a functional single ventricle: Subsequent morbidity and survival
}

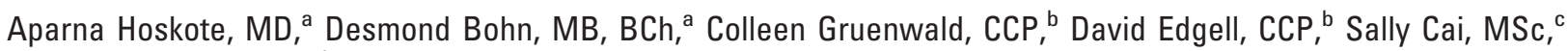
Ian Adatia, MB, ChB, ${ }^{\mathrm{a}, \mathrm{d}}$ and Glen Van Arsdell, $\mathrm{MD}^{\mathrm{c}}$

From the Department of Critical Care Medicine $^{\mathrm{a}}$ and the Divisions of Perfusion Services, ${ }^{\mathrm{b}}$ Cardiovascular Surgery, ${ }^{\mathrm{c}}$ and Cardiology, ${ }^{\mathrm{d}}$ The Hospital for Sick Children and University of Toronto, Toronto, Canada.

Received for publication Aug 1, 2005; revisions received Nov 2, 2005; accepted for publication Nov 28, 2005.

Address for reprints: Ian Adatia, MB, ChB, University of California San Francisco Children's Hospital, 505 Parnassus Ave, Room M-655, San Francisco, CA 94143-0106 (E-mail: ian.adatia@ucsf.edu).

J Thorac Cardiovasc Surg 2006;131:1114-21 $0022-5223 / \$ 32.00$

Copyright $(\odot) 2006$ by The American Association for Thoracic Surgery

doi:10.1016/j.jtcvs.2005.11.035
Objective: We sought to review the outcome of infants with a functional single ventricle receiving postoperative extracorporeal life support.

Methods: We reviewed all patients with a functional single ventricle receiving postoperative extracorporeal life support between January 1997 and May 2003.

Results: We supported 25 infants (age range, 2-139 days; median age, 15 days; weight range, $1.9-5.9 \mathrm{~kg}$; median weight, $3.4 \mathrm{~kg}$ ) with extracorporeal life support. Operative procedures were Norwood stage 1 procedure in 18 patients, modified Blalock-Taussig shunt in 4 patients, bidirectional superior cavopulmonary shunt in 2 patients, and pulmonary vein repair in 1 patient. Indications for extracorporeal life support included cardiac arrest (14/25) and low cardiac output state (11/25). Extracorporeal membrane oxygenation was initiated in 19 patients, with conversion to a ventricular assist device in 7 patients. Ventricular assist device alone was initiated in 6 patients. Survival to decannulation was $76 \%$, with 5 late deaths from multiorgan failure and $56 \%$ intensive care unit survival. Survival to hospital discharge was $44 \%$. On univariate analysis, the presence of arrhythmia before extracorporeal life support $(P=.005)$, renal failure $(P=.0007)$, Candida species-induced sepsis $(P=.026)$, and multiorgan failure $(P=.0009)$ were significant risk factors in the nonsurvivors. Median hospital stay was 43.5 days (range, 6-181 days) for the whole group and 93 days (range, 36-181 days) for survivors. Eight patients completed next stage palliation.

Conclusions: Twenty percent of patients were supported with a ventricular assist device alone, with 50\% conversion to a ventricular assist device from extracorporeal membrane oxygenation. Survival to decannulation was encouraging. Multiorgan failure and risk of invasive infection in the post-extracorporeal membrane oxygenation period mitigate against survival to hospital discharge. Use of extracorporeal life support before cardiac arrest might reduce attrition between decannulation and hospital discharge.

$\mathrm{M}$ edical and surgical strategies for most neonates with a single functional ventricle continue to evolve and improve. Extracorporeal life support (ECLS) has been used successfully to salvage neonates with a functional single ventricle from refractory low cardiac output syndrome postoperatively. ${ }^{1-7}$ Indeed, the elective use of ECLS to support patients after the Norwood stage 1 procedure has been reported. ${ }^{5}$ We report our experience in a single tertiary pediatric cardiac center with patients with a functional single ventricle who have been supported with ECLS after palliative surgery.

We sought to review the outcomes of patients with a functional single ventricle supported with ECLS postoperatively. 


\author{
Abbreviations and Acronyms \\ ACT = activated clotting time \\ BT = Blalock-Taussig \\ ECLS = extracorporeal life support \\ ECMO = extracorporeal membrane oxygenation \\ ICU = intensive care unit \\ LCOS = low cardiac output state \\ RAI = right atrial isomerism \\ TAPVC $=$ total anomalous pulmonary venous \\ connection \\ $\mathrm{VAD}=$ ventricular assist device
}

\section{Methods}

We retrospectively reviewed all available clinical data, including the hospital, surgical, and perfusion records, as well as, all echocardiographic and angiographic studies. Autopsy data, if available, were reviewed.

Throughout the study period, we maintained a primed ECLS circuit with an oxygenator for rapid deployment, with the option to convert to a ventricular assist device (VAD) alone if suitable. In addition, an in-house team was assembled that was capable of starting a patient on ECLS at short notice. We used standard antibiotic coverage for the first 3 days after starting open-chest ECLS. We maintained strict surveillance for infection with daily blood cultures; we did not use regular mediastinal washouts or change vascular lines routinely. We performed alternate-day cranial ultrasonographic scans or sooner if clinical concern was present.

Data are described as frequencies, medians with ranges, and means with standard deviations. Comparison of categoric data was performed by using $\chi^{2}$ or Fisher exact tests. Continuous data were compared by using $t$ tests, paired $t$ tests, and analysis of variance. The Kruskal-Wallis test was used for nonparametric comparisons. Kaplan-Meier "survival" curves were explored to compare "timeto-event" rates. Log-rank tests were used to assess the statistical significance. Statistics were analyzed by using a commercially available software package (SAS version 8.2).

The research and ethics board of the Toronto Hospital for Sick Children approved the study.

\section{Results}

\section{Demographics, Diagnosis, and Operative Details}

Data on demographics, diagnosis, and operative details are shown in Table 1. From January 1997 through June 2003, 25 children (17 male and 8 female children) with a single functional ventricle were supported with ECLS after palliative surgery for a median of 112 hours (range, 13-240 hours). Median age was 15 days (range, 2-139 days), median weight was $3.5 \mathrm{~kg}$ (range, 1.9-5.9 kg), and median gestational age was 40 weeks (range, 32-41 weeks). Five were less than 37 weeks' gestation, and 2 were less than 35 weeks' gestation. Five patients had right atrial isomerism (RAI): 4 with obstructed total anomalous pulmonary venous connection (TAPVC), 3 with pulmonary atresia, 2 with pulmonary stenosis, and 1 with additional subaortic stenosis. All patients with RAI with obstructed TAPVC underwent repair with the sutureless technique with the use of in situ pericardium. ${ }^{8}$ The Norwood stage 1 procedure was performed in 18 patients, of whom 3 had the Sano modification with a right ventricle-to-pulmonary artery shunt.

\section{ECLS Details, Indications, Cause of Arrest, Time of Cannulation, and Duration of ECLS}

Data on ECLS details, indications, cause of arrest, time of cannulation, and duration of ECLS are shown in Table 2.

ECLS circuit. All patients were supported on a Biomedicus Portable Bypass System (Medtronic Perfusion Systems) incorporating the centrifugal pump-based console and a water pump system. A prepackaged tubing set combined with an oxygenator, heat exchanger, constrained vortex pump chamber, and flow probe was used to complete the circuit. Pressure-, temperature-, and oxygen saturationmonitoring devices enhanced the circuit. We used heparinbonded (Carmeda) circuits (Medtronic Perfusion Systems). The oxygenators were silicone membrane lungs (Medtronic extracorporeal membrane oxygenation [ECMO] oxygenators; 13/20) or hollow-fiber Minimax oxygenators (7/20; Medtronic). We used Biomedicus, DLP (Medtronic), Jostra, and Polystan A/S cannulae. A modification of the same circuit without the oxygenator was used when adapted for the VAD. ECLS was commenced in the operating room in 10 patients, on the basis of failure to wean from bypass in 7 patients and electively in 3 patients with RAI-TAPVC. Fourteen were cannulated in the cardiac intensive care unit (ICU) and 1 in the cardiac catheterization laboratory at a median time of 181 hours (range, 1-672 hours) after cardiac surgery. Five were cannulated within 48 hours of surgical intervention. Cannulation was performed through an already open sternum in 21 patients, the sternum was opened for cannulation in 3 patients, and cannulation was transcervical in 1 patient. The indications for ECLS support were cardiac arrest in 14 patients and low cardiac output state (LCOS) refractory to medical management in 11 patients. We defined LCOS as a sustained mixed venous oxygen saturation that remained less than $40 \%$ despite therapy. The median duration of cardiac arrest was 36 minutes (range, 20-60 minutes). The cause of the cardiac arrest was precipitated by poor myocardial function in 10 patients (of whom 5 had associated uncontrollable arrhythmia) and by acute aortopulmonary shunt obstruction in 4 patients $(1.9 \%$ of shunts performed during the study period). Open chest cannulation was performed in all but 1 patient who was cannulated through the neck 16 days after surgical intervention. Two patients after superior cavopulmonary anastomosis were cannulated transternally. A common atrial cannula was placed in one, and an additional cannula was placed in the innominate vein in the other. 
TABLE 1. Demographics, diagnosis, and operative details

\begin{tabular}{|c|c|c|c|c|c|c|c|c|c|}
\hline Patient no. & $\begin{array}{l}\text { Age } \\
\text { (d) }\end{array}$ & $\begin{array}{l}\text { Weight } \\
\text { (kg) }\end{array}$ & Cardiac diagnosis & Operation & $\begin{array}{l}\text { Shunt } \\
\text { size }\end{array}$ & $\begin{array}{c}\text { CPB } \\
(\min )\end{array}$ & $\begin{array}{l}\text { ACC } \\
(\min )\end{array}$ & $\begin{array}{c}\text { Circ A } \\
(\min )\end{array}$ & $\begin{array}{l}\text { Hospital } \\
\text { survivor }\end{array}$ \\
\hline 1 & 3 & 3.5 & HLHS-Unbalanced AVSD & $\begin{array}{l}\text { Stage } 1 \text { Norwood RV-PA } \\
\text { conduit }\end{array}$ & 5.0 & 153 & 65 & 12 & No \\
\hline 2 & 4 & 3.6 & HLHS with LV sinusoids & $\begin{array}{l}\text { Stage } 1 \text { Norwood RV-PA } \\
\text { conduit }\end{array}$ & 5.0 & 145 & 65 & 14 & Yes \\
\hline 3 & 9 & 3.0 & Dextrocardia, LAI, TGA & $\begin{array}{l}\text { Stage } 1 \text { Norwood RV-PA } \\
\text { conduit }\end{array}$ & 5.0 & 180 & 79 & 22 & No \\
\hline 5 & 4 & 2.7 & HLHS, Interrupted arch & Stage 1 Norwood & 3.0 & 312 & 167 & 71 & No \\
\hline 6 & 6 & 3.2 & HLHS & Stage 1 Norwood & 3.5 & 139 & & & Yes \\
\hline 7 & 8 & 3.3 & HLHS & Stage 1 Norwood & 3.5 & 166 & 67 & 20 & No \\
\hline 8 & 8 & 3.2 & HLHS & Stage 1 Norwood & 3.5 & 174 & 56 & & No \\
\hline 9 & 9 & 3.5 & HLHS, AA & Stage 1 Norwood & 3.5 & 252 & 120 & 11 & Yes \\
\hline 14 & 28 & 2.4 & HLHS, AA & Stage 1 Norwood & 3.5 & 227 & 75 & 3 & No \\
\hline 15 & 37 & 2.0 & HLHS, AA & Stage 1 Norwood & 3.0 & 171 & 76 & & Yes \\
\hline 16 & 42 & 3.8 & HLHS & Stage 1 Norwood & 3.5 & 138 & 79 & & Yes \\
\hline 17 & 112 & 4.9 & HLHS & Stage 1 Norwood & 4.0 & 437 & 233 & & Yes \\
\hline 18 & 139 & 4.8 & $\begin{array}{l}\text { DILV, TGA, Aortic } \\
\text { hypoplasia, MS }\end{array}$ & Stage 1 Norwood & 4.0 & 206 & 76 & 1 & Yes \\
\hline 19 & 90 & 4.8 & $\begin{array}{c}\text { Dextrocardia, DOLV, } \\
\text { hypoplastic RV }\end{array}$ & DKS, BCPA, PA plasty & NA & 332 & 18 & & No \\
\hline 20 & 2 & 3.6 & $\begin{array}{l}\text { RAI, PA, AVSD, } \\
\text { obstructed TAPVD }\end{array}$ & $\begin{array}{l}\text { Repair of obstructed } \\
\text { TAPVD, BTS, PA plasty }\end{array}$ & 3.5 & 159 & 62 & & Yes \\
\hline 21 & 60 & 3.6 & $\begin{array}{l}\text { RAI, PA, AVSD, } \\
\text { obstructed TAPVD }\end{array}$ & $\begin{array}{l}\text { Repair of obstructed } \\
\text { TAPVD, s/p BTS }\end{array}$ & 3.5 & 111 & 68 & & Yes \\
\hline 25 & 15 & 2.6 & PA, IVS, hypoplastic RV & Right BTS, PDA ligation & 3.5 & & & & No \\
\hline
\end{tabular}

$C P B$, Cardiopulmonary bypass; $A C C$, aortic crossclamp; Circ $A$, circulatory arrest; HLHS, hypoplastic left heart syndrome; AVSD, atrioventricular septal defect; $R V-P A$, right ventricle to pulmonary artery; $L V$, left ventricle; $L A l$, left atrial isomerism; $T G A$, transposition of the great arteries; $A A$, aortic atresia; $T A$, tricuspid atresia; DILV, double-inlet left ventricle; $M S$, mitral stenosis; $D O L V$, double-outlet left ventricle; $D K S$, Damus-Kaye Stansel; $B C P A$, bidirectional cavopulmonary anastomosis; $P A$, pulmonary atresia; $R A I$, right atrial isomerism; $T A P V D$, total anomalous pulmonary venous drainage; $B T S$, Blalock-Taussig shunt; $s / p$, status post; DORV, double-outlet right ventricle; $A V V$, atrioventricular valve; IVS, intact ventricular septum; PDA, patent ductus arteriosus.

Mode of ECLS support on initiation and subsequent course. We initiated ECLS (ie, support with an oxygenator in 19 patients and as a VAD without an oxygenator in 6 patients). In the former group the oxygenator was removed from the circuit in 7 patients after a median of 48 hours (range, 1-62 hours). Removal of the oxygenator from the ECLS circuit was not associated with mechanical complications. One patient who returned from the operating room on VAD support required addition of the oxygenator in the cardiac critical care unit. The Blalock-Taussig (BT) shunt was clipped in 2 patients because of poor systemic perfusion. The patients who received a BT shunt were managed with high flows (mean, $180 \pm 40 \mathrm{~mL} \cdot \mathrm{kg}^{-1} \cdot \mathrm{min}^{-1}$ ) and afterload reduction with phenoxybenzamine, milrinone, or both. We aimed to maintain a normal arteriovenous oxygen saturation difference with systemic oxygenation levels appropriate for a shunt-dependant patient. The patients who received the Sano shunt were managed with mean flows of $150 \pm$ $20 \mathrm{~mL} \cdot \mathrm{kg}^{-1} \cdot \mathrm{min}^{-1}$. Anticoagulation was maintained by means of continuous infusions of unfractionated heparin, 
TABLE 2. ECLS details, indications, cause of arrest, time of cannulation, and duration of ECLS

\begin{tabular}{|c|c|c|c|c|c|c|c|}
\hline Patient no. & Cardiac diagnosis & ECMO/VAD & $\begin{array}{l}\text { Initiation } \\
\text { of ECLS }\end{array}$ & Indication for ECLS & $\begin{array}{l}\text { Time to ECLS } \\
\text { after OR (h) }\end{array}$ & $\begin{array}{l}\text { Duration of } \\
\text { ECLS (h) }\end{array}$ & $\begin{array}{l}\text { Hospital } \\
\text { survivor }\end{array}$ \\
\hline 1 & $\begin{array}{l}\text { HLHS-Unbalanced } \\
\text { AVSD }\end{array}$ & Only ECMO & $\mathrm{OR}$ & LCOS & NA & 411 & No \\
\hline 2 & HLHS with LV sinusoids & Only ECMO & OR & LCOS & NA & 95 & Yes \\
\hline 3 & Dextrocardia, LAI, TGA & Only ECMO & ICU & CA & 168 & 108 & No \\
\hline 4 & HLHS & Only ECMO & $\mathrm{OR}$ & $\mathrm{CA}$ & NA & 17 & No \\
\hline 5 & HLHS, IAA & Only ECMO & OR & LCOS & NA & 40 & No \\
\hline 6 & HLHS & Only ECMO & ICU & LCOS & 30 & 13 & Yes \\
\hline 7 & HLHS & ECMO to VAD & ICU & CA & 90 & 203 & No \\
\hline 8 & HLHS & ECMO to VAD & $\mathrm{OR}$ & LCOS & NA & 175 & No \\
\hline 9 & HLHS, AA & Only VAD & ICU & CA & 2 & 16 & Yes \\
\hline 10 & HLHS & ECMO to VAD & ICU & CA & 216 & 198 & No \\
\hline 11 & TA, TGA & ECMO to VAD & ICU & Shunt obstruction & 288 & 134 & Yes \\
\hline 12 & HLHS & Only ECMO & ICU & CA & 216 & 120 & Yes \\
\hline 13 & HLHS & Only VAD & ICU & $\mathrm{CA}$ & 84 & 89 & No \\
\hline 14 & HLHS, AA & Only ECMO & ICU & Shunt obstruction & 672 & 104 & No \\
\hline 15 & HLHS, AA & ECMO to VAD & ICU & Shunt obstruction & 312 & 72 & Yes \\
\hline 16 & HLHS & ECMO to VAD & ICU & $\mathrm{CA}$ & 384 & 96 & Yes \\
\hline 17 & HLHS & VAD to ECMO & OR & LCOS & NA & 240 & Yes \\
\hline 18 & $\begin{array}{l}\text { DILV, TGA, aortic } \\
\text { hypoplasia, MS }\end{array}$ & Only ECMO & OR & LCOS, PHT & NA & 58 & Yes \\
\hline 19 & $\begin{array}{c}\text { Dextrocardia, DOLV, } \\
\text { hypoplastic RV }\end{array}$ & Only ECMO & $\mathrm{OR}$ & LCOS & NA & 58 & No \\
\hline 20 & $\begin{array}{l}\text { RAI, PA, AVSD, } \\
\text { obstructed TAPVD }\end{array}$ & Only VAD & OR & LCOS & NA & 96 & Yes \\
\hline 21 & $\begin{array}{l}\text { RAI, PA, AVSD, } \\
\text { obstructed TAPVD }\end{array}$ & Only VAD & OR & LCOS & NA & 168 & Yes \\
\hline 22 & $\begin{array}{c}\text { RAI, PA, TGA, AVSD, } \\
\text { obstructed TAPVD }\end{array}$ & Only VAD & ICU & LCOS & 12 & 192 & No \\
\hline 23 & $\begin{array}{l}\text { RAI, PS, DORV, } \\
\text { obstructed TAPVD }\end{array}$ & ECMO to VAD & ICU & CA & 30 & 96 & No \\
\hline 24 & $\begin{array}{l}\text { RAI, DORV, AVSD, } \\
\text { subpulmonary } \\
\text { stenosis, subaortic } \\
\text { stenosis }\end{array}$ & Only ECMO & ICU & CA & 1 & 136 & No \\
\hline 25 & PA, IVS, hypoplastic RV & Only ECMO & CCL & Shunt obstruction & 216 & 192 & No \\
\hline
\end{tabular}

ECMO, Extracorporeal membrane oxygenation; $V A D$, ventricular assist device; ECLS, extracorporeal membrane oxygenation; OR, operating room; $H L H S$, hypoplastic left heart syndrome; $A V S D$, atrioventricular septal defect; $L C O S$, low cardiac output state; $N A$, not applicable; $L V$, left ventricle; $L A I$, left atrial isomerism; TGA, transposition of the great arteries; ICU, intensive care unit ; $C A$, cardiac arrest; $I A A$, interrupted aortic arch; $A A$, aortic atresia; $T A$, tricuspid atresia; DILV, double-inlet left ventricle; $M S$, mitral stenosis; $P H T$, pulmonary hypertension; $D O L V$, double-outlet left ventricle; $R V$, right ventricle; $P A$, pulmonary atresia; TAPVD, total anomalous pulmonary venous drainage; RAI, right atrial isomerism; DORV, double-outlet right ventricle; IVS, intact ventricular septum; $C C L$, cardiac catheterization laboratory.

which were monitored on the basis of activated clotting time (ACT) and anti-Xa levels. Hourly ACT levels and anti-Xa levels every 12 hours guided the management of anticoagulation on ECLS. The target ACT levels for ECLS were 180 to 200 seconds and for VAD were 140 to 160 seconds with anti-Xa levels between 0.35 and 0.7 $\mathrm{U} / \mathrm{mL}$. We found that monitoring of antithrombin 3 levels and the use of constant plasma infusions in small patients improved the effectiveness of our anticoagulation protocol. We re-explored the mediastinum for bleeding, espe- cially when the ACTs and anti-Xa levels were within the target range or there was associated hemodynamic instability. Cardiac catheterization was performed in 13 patients supported with ECLS. We detected residual anatomic lesions in 3 patients (neoaortic obstruction, thrombosed BT shunt, and precoronary obstruction in the native ascending aorta) and significant hemodynamic lesions in 2 patients (one with severe atrioventricular valve regurgitation and one with both atrioventricular and neoaortic regurgitation). In 2 patients with RAI-TAPVC, cryoablation of 


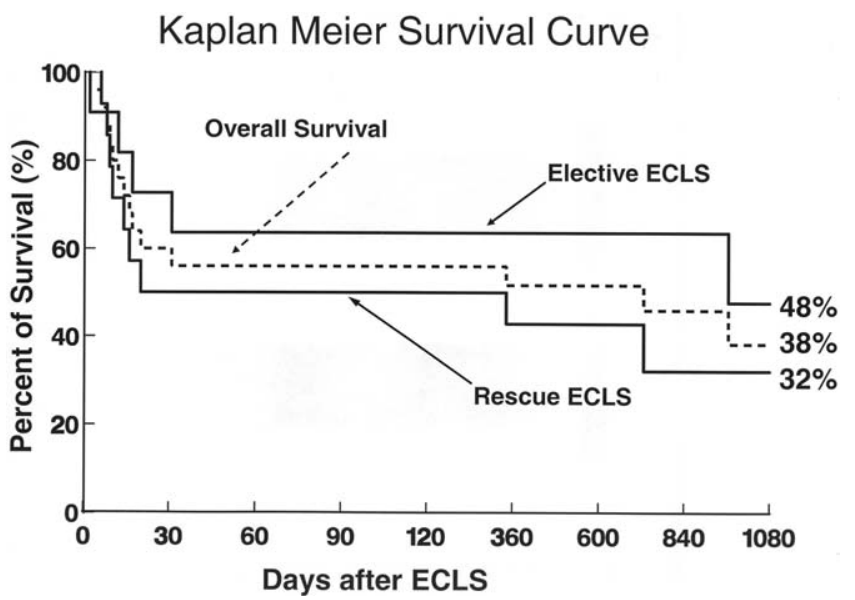

Figure 1. The Kaplan-Meier survival curve for all patients supported with ECLS. The estimated overall survival is $38 \%$ (confidence interval, $\mathbf{2 8} \%-50 \%$ ) at 1000 days after ECLS support (dotted lines), that for those supported electively is $48 \%$ (confidence interval, 31\%-65\%; single straight line), and that for those supported as rescue after cardiac arrest is $\mathbf{3 2} \%$ (confidence interval, 20\%-47\%; bold line). The actuarial overall survival at 1000 days was $9(36 \%)$ of 25 patients. On log-rank analysis, the increased survival in those supported electively was not statistically significant $(P=.17)$.

abnormal conduction pathways was performed during ECLS.

\section{Complications on ECLS}

Significant bleeding requiring surgical exploration occurred in $20 \%$ of patients supported with a VAD compared with $45 \%$ of patients on full ECMO support. Renal failure (defined as increased serum creatinine value above the standard laboratory reference range for the relevant age group and urine output of less than $1 \mathrm{~mL} \cdot \mathrm{kg}^{-1} \cdot \mathrm{h}^{-1}$ ) was present in $16(64 \%)$ of 25 patients. Peritoneal dialysis was performed in 9 patients, continuous venovenous hemofiltration in 2 patients, and slow continuous ultrafiltration in 5 patients. Ten had sepsis (10/25 [40\%]) with positive blood cultures. Six (1 with Pseudomonas species and 5 with systemic Candida species infections) subsequently died. Adverse neurologic events occurred in 7 (28\%) of 25 patients. Intracerebral hemorrhage identified by means of cranial ultrasonography occurred in 3 patients (left parietal, thalamic, and intraventricular), cerebral infarcts were seen in 2 patients, and 2 patients had seizures. Six of the 7 died subsequently. There were no neurologic complications in the survivors supported with a VAD alone. Respiratory complications occurred in 3 patients who failed conversion to $\mathrm{VAD}$, but all were decannulated and survived ICU discharge.

The overall median duration of mechanical ventilation was 504 hours (range, 144-2496 hours), and that in survi-
TABLE 3. Pre-ECLS, ECLS, and post-ECLS variables and hospital survival

\begin{tabular}{lccc}
\hline Variable & $\begin{array}{c}\text { Hospital } \\
\text { survivor } \\
(\mathbf{n}=\mathbf{1 1})\end{array}$ & $\begin{array}{c}\text { Hospital } \\
\text { nonsurvivor } \\
(\mathbf{n}=\mathbf{1 4})\end{array}$ & $\begin{array}{c}\boldsymbol{P} \\
\text { value }\end{array}$ \\
\hline Cardiac arrest & $5 / 11(45 \%)$ & $9 / 14(64 \%)$ & .3464 \\
Arrhythmia before ECLS & $0 / 11(0 \%)$ & $7 / 14(50 \%)$ & $.0057^{*}$ \\
Shunt open & $11 / 11(100 \%)$ & $2 / 14(14 \%)$ & .1742 \\
Oxygenator not present & $7 / 11(58 \%)$ & $6 / 14(42 \%)$ & .3019 \\
$\quad$ or removed & & & \\
More than 120 h on ECLS & $3 / 11(27 \%)$ & $7 / 14(50 \%)$ & .4954 \\
Renal failure & $3 / 11(27 \%)$ & $13 / 14(92 \%)$ & $.0007^{*}$ \\
Sepsis & $4 / 11(36 \%)$ & $6 / 14(42 \%)$ & .7422 \\
Candida species-induced & $0 / 11(0 \%)$ & $5 / 14(35 \%)$ & $.0267^{*}$ \\
$\quad$ sepsis & & & \\
Multiorgan failure $(\geq 2)$ & $0 / 11(0 \%)$ & $9 / 14(64 \%)$ & $.0009^{*}$ \\
Arrhythmia after ECLS & $1 / 11(9 \%)$ & $6 / 14(42 \%)$ & .0620 \\
\hline
\end{tabular}

ECLS, Extracorporeal life support. *Significant difference at $P<.05$.

vors was 828 hours (range, 264-2496 hours). Three patients failed initial decannulation, 1 with LCOS and 2 with arrhythmia and subsequent LCOS; all 3 were resupported on ECMO, 1 was bridged to transplantation, and 2 died later, both of whom were unsuitable candidates for transplantation.

\section{RAI-TAPVC Subgroup}

Five infants with complex RAI (median age, 62 days; range, 2-120 days; median weight, $3.6 \mathrm{~kg}$; range, $3.1-5.9 \mathrm{~kg}$ ) were supported on ECLS. Three were supported electively on a VAD for a median duration of 168 hours (range, 96-192 hours). Two were supported on ECMO as rescue after cardiac arrest. Two underwent cryoablation during ECLS for refractory tachyarrhythmias. The 2 supported after cardiac arrest died, and those supported electively were discharged from the critical care unit. One was an expremature baby with complex medical issues who died before hospital discharge.

ICU, Hospital Survival, and Overall Survival Until the End of the Study

Data on ICU, hospital survival, and overall survival until the end of study are shown in Figure 1. Overall, 19 (75\%) of 25 patients survived decannulation from mechanical support. In 6 patients ECLS support was withdrawn. None of these 6 patients recovered cardiac function, and their course was complicated by intractable arrhythmias in 2 patients, multiorgan failure in 2 patients, and systemic fungal infection in 2 patients (Tables 3 and 4). The average duration of ECLS in this group was 181 hours. Five died after decannulation after a median of 9 days (range, 5-23 days) after decannulation, all with multiorgan failure complicated by systemic infection in 4 (Pseudomonas species in 1 and Candida species in 3) and impaired pulmonary blood flow related to 
TABLE 4. Pre-ECLS, ECLS, and post-ECLS variables and survival

\begin{tabular}{|c|c|c|c|}
\hline Variable & $\begin{array}{c}\text { Hospital } \\
\text { survivor } \\
\text { (n = 11), } \\
\text { median (range) }\end{array}$ & $\begin{array}{c}\text { Hospital } \\
\text { nonsurvivor } \\
\text { (n = 14), } \\
\text { median (range) }\end{array}$ & $\begin{array}{c}P \\
\text { value }\end{array}$ \\
\hline Age (d) & $17(2-139)$ & $15(3-120)$ & .5694 \\
\hline Weight (kg) & $3.6(2-4.9)$ & $3.2(1.9-5.9)$ & .1741 \\
\hline CPB (min) & $155(111-437)$ & $180(85-332)$ & .2289 \\
\hline Aortic crossclamp (min) & 72 (37-233) & $65(18-167)$ & .2940 \\
\hline Circulatory arrest (min) & $1(1-14)$ & $31(3-71)$ & $.0072^{*}$ \\
\hline $\begin{array}{l}\text { Time to cannulation } \\
\text { after operation }(\mathrm{h})\end{array}$ & $252(2-384)$ & $90(1-672)$ & .2207 \\
\hline $\begin{array}{l}\text { Duration of cardiac } \\
\text { arrest (min) }\end{array}$ & $40(29-45)$ & $35(20-60)$ & .5909 \\
\hline $\begin{array}{l}\text { Lactate level before } \\
\text { ECLS }\end{array}$ & $9(2-21)$ & $11(2-24)$ & .2905 \\
\hline Duration of ECLS (h) & $96(13-240)$ & $122(17-411)$ & .3118 \\
\hline
\end{tabular}

$E C L S$, Extracorporeal life support; $C P B$, cardiopulmonary bypass. *Significant difference at $P<.05$.

a thrombosed shunt in 1 patient. Fourteen patients were discharged from the cardiac critical care unit (survival rate of 56\%). Three died after discharge from the cardiac critical care unit but before discharge from the hospital, 1 with RAI who had sepsis after line-related thrombus, 1 with hypoplastic left heart syndrome with severe neurologic impairment, and 1 with hypoplastic left heart syndrome with central core myopathy, aqueduct stenosis, and increased intracranial pressure. The median duration of critical care unit stay of survivors was 50 days (range, 12-120 days), and that in nonsurvivors was 18 days (range, 6-32 days). The median duration of hospital stay in the group who survived to hospital discharge was 97 days (range, 36-181 days). Survival to hospital discharge was $44 \%$.

The median follow-up in this series has been 27 months (range, 7-50 months). Two patients died 3 months after initial hospital discharge, 1 with decreased ventricular function and progressive pulmonary vein stenosis and 1 with poor ventricular function after bidirectional superior cavopulmonary anastomosis. Among the 9 survivors to date, 8 have completed second-stage palliation, and 1 has undergone cardiac transplantation. A Kaplan-Meier survival curve was constructed to examine the estimated overall survival (Figure 1). The estimated overall survival at 1000 days since ECLS was 38\%, whereas the actuarial overall survival was $9(36 \%)$ of 25 patients. On log-rank analysis, the increased survival in those supported electively was not statistically significant $(P=.17)$.

\section{Discussion}

This is the first review of ECLS in children after the staged single-ventricle palliation, including Norwood stage 1 pro- cedure, bidirectional cavopulmonary anastomosis, and repair of obstructed pulmonary veins in complex RAI. This review, although a single-center experience, supports previous reports that ECLS, with and without an oxygenator, salvages some patients with a functional single ventricle in the immediate postoperative period. We found that one fifth of patients could be supported with a VAD alone, and nearly half were converted to a VAD from ECMO, which might reduce the complications associated with a membrane oxygenator. The risks of bleeding leading to exploration were considerably less compared with those seen in patients supported with ECMO. However, we were unable to show improved survival or freedom from organ dysfunction with the use of a VAD alone compared with ECMO. We speculate that with larger numbers of patients the combination of reduced hemorrhage, blood product use, and the advantage of a clinical substrate that tolerates support with a VAD might improve survival. Effective mechanical support could be provided without the use of the oxygenator while keeping the aortopulmonary shunt open and maintaining high pump flows. Clipping the shunt was unnecessary, and the 2 patients who had the shunt clipped died. This is comparable with other reports in the literature showing that survival is higher if the shunt is left open. ${ }^{4,9}$ Support with a VAD appeared to be most effective for isolated ventricular dysfunction with adequate oxygenation.

The outcome of patients with right isomerism with or without obstructed abnormal pulmonary venous drainage is uniformly poor. ${ }^{10-12}$ The elective use of VAD support in this group of infants might have a role to play in the immediate postoperative period. However, improving early and midterm outcomes for this complex group of patients is challenging, and there continues to be high morbidity and mortality.

In the current cohort of patients, we found that the median time of acute deterioration leading to cardiac arrest and ECLS support was 181 hours, which is 7.5 days after surgical intervention. This highlights that the vulnerable critical period after surgical intervention is not limited to the first 24 to 48 hours, as reported previously. Wright and colleagues ${ }^{13}$ reported that a dangerous increase in systemic vascular resistance could occur remote from the initial operation. In our experience afterload reduction is crucial in the early postoperative management after the traditional stage 1 Norwood procedure (BT shunt), and continued afterload reduction therapy might be required to prevent late cardiovascular collapse. ${ }^{14}$

Among the pre-ECLS variables, severe refractory tachydysrhythmia as a reflection or cause of poor ventricular function was a significant predictor of poor survival. The combination of LCOS and negative inotropic drugs used to control the tachydysrhythmia are poorly tolerated after the Norwood stage 1 procedure. Early support of patients with 
a tachydysrhythmia with ECLS might permit rhythm control before cardiac arrest. The tendency for survival was higher if ECLS was initiated electively (55\% vs 36\%), but this was not statistically significant. Jaggers and associates ${ }^{9}$ found almost $100 \%$ mortality if ECMO was instituted during cardiac arrest. Timely institution of support can limit end-organ damage. Morbidity, mainly caused by multiorgan failure and sepsis after decannulation, however, is a significant problem resulting in long intensive care and hospital stays and significant time-related attrition. In this cohort multiorgan failure and sepsis contributed to significant morbidity. More than half of the patients in this series were supported on ECLS after cardiac arrest, which can increase the risks of multiorgan failure. We found that multiple organ system failure (defined as the failure of at least 2 organ systems, $\left.{ }^{15} P<.0009\right)$ and renal failure $(P<.0007)$ in particular were significant risk factors for death among the nonsurvivors. Many studies have shown that renal failure is an independent factor predisposing to increased mortality. ${ }^{3,4,9,16}$ In this study, although the decannulation from ECLS was encouraging, particularly in the high-risk subgroup with RAI-TAPVC, the attrition from the time of decannulation to hospital discharge was a major issue. The median overall survival to hospital discharge for patients with a single ventricle supported on ECLS in the reported literature is $40 \%$ (range, 33\%-64\%). ${ }^{2,4,6,9,17-21}$ Our results compare favorably at $44 \%$. In our study the tendency for survival was higher when a VAD alone was used $(60 \%$ vs $40 \%)$ and if the duration of ECLS was less than 120 hours (72\% vs $50 \%$ ), but this was not statistically significant. The relatively small number of patients and the retrospective design of the study preclude use of multivariate analysis.

In a multivariate analysis of risk factors for operative outcome for stage 1 operations in 158 patients, Gaynor and colleagues $^{18}$ identified that ECLS support was one of the predictors of operative mortality $(P<.001)$. In a recent study from the same institution reviewing the outcome of all patients supported with ECLS over a 5-year period, ${ }^{6}$ singleventricle physiology and failure to separate from cardiopulmonary bypass were not associated with an increased risk of mortality. The factors identified that increased the probability of mortality in postoperative patients were age less than 1 month, male sex, longer duration of mechanical ventilation before ECLS, and development of renal or hepatic dysfunction during ECLS. Continuing multiorgan failure, infection, and thrombosis in the post-ECLS phase are risk factors for prolonged critical care unit stay, hospital stay, and late mortality. Montgomery and coworkers, ${ }^{22}$ in their review of 59 children treated with ECMO after cardiopulmonary bypass over a 9-year period, reported that progressive multiple organ system dysfunction and development of a nosocomial infection were significantly associated with death.
This warrants aggressive management of LCOS, anticoagulation, and treatment and prevention of systemic infections.

The Extracorporeal Life Support Organization Registry has reported data over a 4-year period from 1996 through 2000 documenting the substantial increase in neonatal ECLS. Survival rates have remained constant at $35 \% .^{23}$ However, survival rates in the disadvantaged patients with a single ventricle was not significantly lower than in the biventricular group of cardiac patients.

There is no doubt that in a small subset of patients after functional single-ventricle palliation, use of ECLS positively affects survival. Thus ECLS will remain an important resource, albeit highly technical and expensive, when faced with adverse hemodynamics in the immediate postoperative period. With further advances in the surgical management of hypoplastic left and right heart syndrome, optimum ECLS support in the initial postoperative period will be an important treatment option until identification of residual correctable lesions and recovery of the stressed myocardium. The long-term neurologic morbidity is significant, ${ }^{24,25}$ and survivors might have cognitive impairment, motor impairment, or both and require prolonged care, with major implications on health care resources. ${ }^{26}$

A second run of ECLS carried a high mortality. However, it was difficult to predict which patients might benefit without recourse to transplantation.

We identified that longer periods of circulatory arrest are associated with reduced survival (Table 4). We suggest that techniques to limit prolonged periods of total circulatory arrest by providing regional perfusion might be important determinants of short-term outcome.

Early identification, recognition, and management of LCOS is crucial because early use of ECLS before cardiac arrest when LCOS is present, especially in the presence of a tachydysrhythmia, might reduce the morbidity related to multiorgan failure between decannulation and hospital discharge. Strategies to improve survival to hospital discharge are required to justify the continued use of ECLS in this patient group, especially as critical care unit and hospital stays are prolonged.

\section{References}

1. Azakie T, Merklinger SL, McCrindle BW, Van Arsdell GS, Lee KJ, Benson LN, et al. Evolving strategies and improving outcomes of the modified Norwood procedure: a 10-year single-institution experience. Ann Thorac Surg. 2001;72:1349-53.

2. Darling EM, Kaemmer D, Lawson DS, Jaggers JJ, Ungerleider RM. Use of ECMO without the oxygenator to provide ventricular support after Norwood Stage I procedures. Ann Thorac Surg. 2001;71:735-6.

3. Drinkwater DC Jr, Aharon AS, Quisling SV, Dodd D, Reddy VS, Kavanaugh-McHugh A, et al. Modified Norwood operation for hypoplastic left heart syndrome. Ann Thorac Surg. 2001;72:2081-7.

4. Pizarro C, Davis DA, Healy RM, Kerins PJ, Norwood WI. Is there a role for extracorporeal life support after stage I Norwood? Eur J Car diothorac Surg. 2001;19:294-301. 
5. Ungerleider RM, Shen I, Yeh T, Schultz J, Butler R, Silberbach M, et al. Routine mechanical ventricular assist following the Norwood procedure-improved neurologic outcome and excellent hospital survival. Ann Thorac Surg. 2004;77:18-22.

6. Morris MC, Ittenbach RF, Godinez RI, Portnoy JD, Tabbutt S, Hanna $\mathrm{BD}$, et al. Risk factors for mortality in 137 pediatric cardiac intensive care unit patients managed with extracorporeal membrane oxygenation. Crit Care Med. 2004;32:1061-9.

7. Kulik TJ, Moler FW, Palmisano JM, Custer JR, Mosca RS, Bove EL, et al. Outcome-associated factors in pediatric patients treated with extracorporeal membrane oxygenator after cardiac surgery. Circulation. 1996;94(suppl):II63-8.

8. Najm HK, Caldarone CA, Smallhorn J, Coles JG. A sutureless technique for the relief of pulmonary vein stenosis with the use of in situ pericardium. J Thorac Cardiovasc Surg. 1998;115:468-70.

9. Jaggers JJ, Forbess JM, Shah AS, Meliones JN, Kirshbom PM, Miller $\mathrm{CE}$, et al. Extracorporeal membrane oxygenation for infant postcardiotomy support: significance of shunt management. Ann Thorac Surg. 2000;69:1476-83.

10. Cheung YF, Cheng VY, Chau AK, Chiu CS, Yung TC, Leung MP. Outcome of infants with right atrial isomerism: is prognosis better with normal pulmonary venous drainage? Heart. 2002;87:146-52.

11. Azakie A, Merklinger SL, Williams WG, Van Arsdell GS, Coles JG, Adatia I. Improving outcomes of the Fontan operation in children with atrial isomerism and heterotaxy syndromes. Ann Thorac Surg. 2001; 72:1636-40.

12. Gilljam T, McCrindle BW, Smallhorn JF, Williams WG, Freedom RM. Outcomes of left atrial isomerism over a 28 -year period at a single institution. J Am Coll Cardiol. 2000;36:908-16.

13. Wright GE, Crowley DC, Charpie JR, Ohye RG, Bove EL, Kulik TJ. High systemic vascular resistance and sudden cardiovascular collapse in recovering Norwood patients. Ann Thorac Surg. 2004;77:48-52.

14. De Oliveira NC, Ashburn DA, Khalid F, Burkhart HM, Adatia IT, Holtby HM, et al. Prevention of early sudden circulatory collapse after the Norwood operation. Circulation. 2004;110(suppl 1):II133-8.

15. Wilkinson JD, Pollack MM, Ruttimann UE, Glass NL, Yeh TS. Outcome of pediatric patients with multiple organ system failure. Crit Care Med. 1986;14:271-4.
16. Kolovos NS, Bratton SL, Moler FW, Bove EL, Ohye RG, Bartlett RH, et al. Outcome of pediatric patients treated with extracorporeal life support after cardiac surgery. Ann Thorac Surg. 2003;76:1435-42.

17. Aharon AS, Drinkwater DC Jr, Churchwell KB, Quisling SV, Reddy VS, Taylor M, et al. Extracorporeal membrane oxygenation in children after repair of congenital cardiac lesions. Ann Thorac Surg. 2001;72: 2095-102.

18. Gaynor JW, Mahle WT, Cohen MI, Ittenbach RF, DeCampli WM, Steven JM, et al. Risk factors for mortality after the Norwood procedure. Eur J Cardiothorac Surg. 2002;22:82-9.

19. Pizarro C, Davis DA, Kerins PJ, Raphaely RC, Spurrier EA, Norwood WI. Extracorporeal membrane oxygenation for neonates with single ventricle and parallel circulations. J Heart Lung Transplant. 2001;20: 239-40.

20. Thuys CA, Mullaly RJ, Horton SB, O'Connor EB, Cochrane AD, Brizard CP, et al. Centrifugal ventricular assist in children under $6 \mathrm{~kg}$. Eur J Cardiothorac Surg. 1998;13:130-4.

21. Walters HL 3rd, Hakimi M, Rice MD, Lyons JM, Whittlesey GC, Klein MD. Pediatric cardiac surgical ECMO: multivariate analysis of risk factors for hospital death. Ann Thorac Surg. 1995;60:329-37.

22. Montgomery VL, Strotman JM, Ross MP. Impact of multiple organ system dysfunction and nosocomial infections on survival of children treated with extracorporeal membrane oxygenation after heart surgery. Crit Care Med. 2000;28:526-31.

23. Hintz SR, Benitz WE, Colby CE, Sheehan AM, Rycus P, Van Meurs KP. Utilization and outcomes of neonatal cardiac extracorporeal life support: 1996-2000. Pediatr Crit Care Med. 2005;6:33-8.

24. Chow G, Koirala B, Armstrong D, McCrindle B, Bohn D, Edgell D, et al. Predictors of mortality and neurological morbidity in children undergoing extracorporeal life support for cardiac disease. Eur J Cardiothorac Surg. 2004;26:38-43.

25. Hamrick SE, Gremmels DB, Keet CA, Leonard CH, Connell JK, Hawgood S, et al. Neurodevelopmental outcome of infants supported with extracorporeal membrane oxygenation after cardiac surgery. $P e$ diatrics. 2003;111:e671-5

26. Van Litsenburg R, De Mos N, Edgell D, Gruenwald C, Bohn DJ, Parshuram CS. Resource use and health outcomes of paediatric extracorporeal membrane oxygenation. Arch Dis Child Fetal Neonatal Ed. 2005;90:F176-7.

\section{JTCVS On-Line Manuscript Submission and Review}

The Journal of Thoracic and Cardiovascular Surgery requires authors and reviewers to submit all new and revised manuscripts and reviews via Editorial Manager. Point your browser to http://jtcvs.editorialmanager.com, log in as author or reviewer (as appropriate), and follow the instructions provided.

To retrieve your username and password, click "Forget your password?" on the Editorial Manager log-in page.

If you have questions or experience problems uploading your manuscript or review, please contact the editorial office:

Telephone: 215-762-1854

E-mail: jtcvs@drexel.edu 